\title{
Drug Development to Protozoan Diseases
}

\author{
Lianet Monzote $^{*}, 1$ and Afshan Siddiq ${ }^{2}$ \\ ${ }^{1}$ Parasitology Department, Institute of Medicine Tropical "Pedro Kourí”, Havana City, Cuba \\ ${ }^{2}$ Department of Pharmacology, University of Karachi, Karachi, Pakistan
}

\begin{abstract}
The diseases caused by protozoan parasite are responsible for considerable mortality and morbidity, affecting more than 500 million of people in the world. The epidemiological control of protozoan is unsatisfactory due to difficulties of vector and reservoir control; while the progress in the development of vaccine tends to be slow and arduous. Currently, the chemotherapy remains essential component of both clinical management and disease control programmer in endemic areas. The drugs in use as anti-protozoan agents were discovered over 50 years and a number of factors limit their utility such as: high cost, poor compliance, drug resistance, low efficacy and poor safety. In the recent years, the searches about the development of new drugs against protozoa parasite have been increased. This special issue of The Open Medicinal Chemistry Journal will present some of developments in this field with the aim to shown the significant advances in the discovery of new anti-protozoan drugs
\end{abstract}

Keywords: Anti-infective, anti-protozoan, drugs.

\section{INTRODUCTION}

Protozoa parasites are composed by a very diverse group of unicellular eukaryotic organism from Protista kingdom, which present nuclei and other structures similar to animals. The main infections in human are due to protozoan of Plasmodium, Trypanosoma and Leishmania genus. Others agents with medical importance exist, such as intestinal protozoa, Toxoplasma gondii and Trichomonas vaginalis. The protozoan have been characterized as a diverse polyphyletic group that present a wide range of epidemiology characteristics and clinic manifestation in different geographic zones, particularly in tropics and subtropics from developing countries (Table 1) [1-4].

The diseases caused by protozoan parasite are responsible for considerable mortality and morbidity, affecting more than 500 million of people in the world (Table 2). The history of protozoa infections in humans teaches us that improved nutrition, economic development and public health measures are probably the deciding factors in increasing diseases in the tropics $[4,5]$.

The study of protozoa biology has attracted the attention not only because they are fascinating organism, but also due to the need of finding tools and developing strategies to decrease the remarkable social and economic burden they cause on human societies [6]. The control of protozoan disease requires a complex interplay of activities in the fields of public health, education political will and medical science. However, the epidemiological control of protozoan is unsatisfactory due to difficulties of vector and reservoir control;

*Address correspondence to this author at the Departamento de Parasitología, Instituto de Medicina Tropical "Pedro Kourî", Apartado Postal No. 601, Marianao 13. Ciudad Habana, Cuba; Tel: +5372020650 ;

Fax: +53 7 2046051; E-mail: monzote@ipk.sld.cu while the progress in the development of vaccine tends to be slow and arduous. Currently, the chemotherapy remains essential component of both clinical management and disease control programmer in endemic areas [4].

\section{CURRENT DRUGS TO PROTOZOAN DISEASES}

Since the decade of 1930 was discoveries the conventional drugs against protozoa disease, which presents general characteristics such as: (a) the compounds are formed by a low number of elements that including carbon, oxygen and nitrogen; while other elements are only present in specific structures, per example the sulphur; (b) the inorganic compounds are scare, although can be used the arsenic and antimonies; (c) the annular structure are very common and the benzene are present in a high percent of compounds or have nitrogen; (d) the methyl, hydroxyl and amine group are very frequently; while the sulphydryl radical is absent [7]. Current drugs in use as anti-protozoan agents were discovered over 50 years. A number of factors limit the utility of existing drugs (Table 3) in resource-poor setting, such as high cost, poor compliance, drug resistance, low efficacy and poor safety $[1,2,5]$.

\section{DRUG DEVELOPMENT TO PROTOZOAN DISEASES}

There is still a great need for drug development against protozoan diseases. The past 20 years has seen a significant increase in our basic knowledge of protozoa parasite. The currently search to develop new drugs have been facilitated by advances in sciences, especially in the field of parasite genomics (identification of unique metabolic pathways and key enzyme of the protozoa), chemistry methodologies (high-performance liquid chromatography (HPLC), nuclear magnetic resonance (NMR) and mass spectrometry) and bioinformatics tools (quantitative structure-activity relation 
Table 1. General Features of Main Protozoan Parasitic Diseases that Affect the Human Health

\begin{tabular}{|c|c|c|c|}
\hline Disease & $\begin{array}{l}\text { Some Representative Etio- } \\
\text { logical Agents }\end{array}$ & Geographical Localization & Clinical Features \\
\hline Malaria & $\begin{array}{l}\text { Plasmodium falciparum, } \\
\text { P. vivax }\end{array}$ & $\begin{array}{l}\text { Over } 100 \text { countries in the } \\
\text { tropic and subtropics }\end{array}$ & $\begin{array}{c}\text { Fever, shivering, cough, respiratory distress, } \\
\text { pain in the joints, headache, watery diarrhea, vomiting, } \\
\text { convulsions severe anemia }\end{array}$ \\
\hline African trypanosomiasis & Trypanosoma brucei & $\begin{array}{c}36 \text { countries in sub-Sahara } \\
\text { Africa }\end{array}$ & $\begin{array}{c}\text { Initial haemolytic phase (fever, joint pains followed by } \\
\text { neurological disorder, somnolence }\end{array}$ \\
\hline Chagas disease & Trypanosoma cruzi & $\begin{array}{l}\text { From northem Mexico to } \\
\text { South Argentina }\end{array}$ & $\begin{array}{c}\text { Acute phase (fever and splenomegaly) } \\
\text { Chronic phase (irreversible damage to heart, esophagus } \\
\text { and colon) }\end{array}$ \\
\hline Leishmaniasis & $\begin{array}{l}\text { Leishmania donovani, } L . \\
\text { major, L. mexicana, } L . \\
\text { braziliensis }\end{array}$ & $\begin{array}{l}\text { Over } 88 \text { countries in tropic and } \\
\text { subtropics }\end{array}$ & $\begin{array}{l}\text { Skin ulcers, mucocutaneous complications and visceral } \\
\text { diseases (hepatosplenomegaly) }\end{array}$ \\
\hline Trichomoniasis & Trichomonas vaginalis & Worldwide & $\begin{array}{l}\text { Vaginal discharge, odor and edema or } \\
\text { erythema. }\end{array}$ \\
\hline Intestinal protozoan & $\begin{array}{l}\text { Giardia lamblia, Enta- } \\
\text { moeba histolytica, } \\
\text { Cryptosporidium parvum, } \\
\text { Cyclospora cayetanensis }\end{array}$ & Worldwide & $\begin{array}{l}\text { Hematuria, anemia, impaired growth. Renal, hepatic and } \\
\text { spleen failure }\end{array}$ \\
\hline
\end{tabular}

Table 2. Summary of Statistics for Damage Caused by Main Parasitic Diseases

\begin{tabular}{|c|c|c|c|}
\hline Disease & Population at Risk $\left.(\mathbf{x 1 0})^{6}\right)$ & Number of People Infected $(\mathbf{x 1 0})$ & Number of Death $\left.(\mathbf{x 1 0})^{\mathbf{3}}\right)$ \\
\hline \hline Malaria & $\sim 2000$ & $\sim 300$ & $\sim 1000-2000$ \\
\hline African trypanosomiasis & $\sim 60$ & $\sim 0.3-0.5$ & $\sim 50$ \\
\hline Chagas disease & $\sim 40$ & $\sim 17$ & $\sim 21$ \\
\hline Leishmaniasis & $\sim 350$ & $\sim 2$ & $\sim 59$ \\
\hline Intestinal protozoans & $>1000$ & $\sim 450$ & $\sim 40-100$ \\
\hline
\end{tabular}

Table 3. Limitations of Currently Used Drugs for Main Protozoan Diseases

\begin{tabular}{|c|c|c|}
\hline \multirow{2}{*}{ Disease } & Some Current Used Drugs & Limitations \\
\hline \hline \multirow{2}{*}{ Malaria } & Chloroquine, 1945 & Resistance \\
\cline { 2 - 3 } & Artemisin, 1994 & Compliance, cost, manufacture \\
\hline \multirow{2}{*}{ African trypanosomiasis } & Suramin, 1920 & Safety, not effective in late-stage diseases, injectable \\
\cline { 2 - 3 } & Pentamidine, 1939 & Safety, resistance, not effective in late-stage diseases, injectable \\
\cline { 2 - 3 } & Melarsoprol, 1949 & Safety, resistance, injectable \\
\hline
\end{tabular}


Table 3. Contd....

\begin{tabular}{|c|c|c|}
\hline \multirow{2}{*}{ Disease } & Some Current Used Drugs & Limitations \\
\hline \hline \multirow{2}{*}{ Chagas disease } & Eflornithine, 1991 & Cost, injectable, only effective against T. gambiense \\
\cline { 2 - 3 } & Nifurtimox, 1970 & Safety, long treatment, compliance, activity limited to acute stage of disease \\
\hline \multirow{2}{*}{ Leishmaniasis } & Benznidazole, 1974 & Safety \\
\cline { 2 - 3 } & Pentamidine, 1939 & Safety, resistance, injectable \\
\cline { 2 - 3 } & Antimonials, 1950 & Safety, resistance, injectable \\
\cline { 2 - 3 } & Liposomal amphotericin B, 1990 & Conjectable \\
\hline \multirow{2}{*}{ Toxoplasmosis } & Miltefosine, 2002 & Safety, only in combined therapy \\
& Sulfonamides, 1932 & Safety, Contraindicated in pregnancy \\
\cline { 2 - 3 } & Pyrimethamine, 1951 & Resistance \\
\hline \multirow{2}{*}{ Trichomoniasis } & Metronidazole, 1955 & Resistance \\
\hline
\end{tabular}

ship (QSAR) modeling techniques) [8-12]. In parallel, recent development have been increased thanks to dedicated academic, public initiatives, private-public partnerships, pharmaceutical industry and the experience of public health care organizations that focus on various aspects of drug discovery for infectious diseases, including the injection of new funds into this research area $[13,14]$. Different strategies have been defined to develop new anti-protozoan drugs in short/medium time (optimization of therapy with existing drugs, development of analogs of current drugs, combination therapy with conventional drugs and identification of agents to use against other indications) and in large time (search new targets and rational drug design and natural products) [15].

This special issue of The Open Medicinal Chemistry Journal will present some of developments in this field with the aim to shown the significant advances in the discovery of new anti-protozoan drugs

\section{REFERENCES}

[1] Fennell, B.J.; Naughton, J.A.; Barlow, J.; Brennan, G.; Fairweather, I.; Hoey, E.; McFerran, N.; Trudgett, A.; Bell, A. Microtubules as antiparasitic drug targets. Expert Opin. Drug Discov., 2008, 3, 501-518.

[2] Pink, R.; Hudson, A.; Mouriés, M.A.; Bendig, M. Opportunities and challenges in antiparasitic drug discovery. Nat. Rev. Drug Discov., 2005, 4, 727-740.
[3] Tekwani, B.L.; Walker, L.A. 8-Aminoquinolines: future role as antiprotozoal drugs. Curr. Opin. Infect. Dis., 2006, 19, 623-631.

[4] Watkins, B.M. Drugs for the control of parasitic diseases: current status and development. Trends Parasitol., 2003, 19, 477-478.

[5] Dupouy-Camet, J. New drugs for the treatment of human parasitic protozoa. Parasitologia, 2004, 46, 81-84.

[6] Cooper, R.A.; Carucci, D.J. Proteomic approaches to studying drug targets and resistance in Plasmodium. Curr. Drug Targets Infect. Disord., 2004, 4, 41-51.

[7] Aparicio, P.; Rodríguez, E.; Gárate, T.; Molina, R.; Soto, A.; Alvar, J. Terapêutica antiparasitária. Enferm. Infecc. Microbiol. Clin., 2003, 21, 579-594.

[8] Cowman, A.F.; Crabb, B.S. Functional genomics: identifying drug targets for parasitic diseases. Trends Parasitol., 2003, 19, 538-543.

[9] Bleicher, K.H.; Bohm, H.J.; Muller, K.; Alanine, A.I. Hit and lead generation: beyond high-throughput screening. Nat. Rev. Drug Discov., 2003, 2, 369-378.

[10] Kissinger, J.C. A tale of three genomes: the kinetoplastids have arrived. Trends Parasitol., 2006, 22, 240-243.

[11] Morales, A.; Rodríguez-Borgues, J.E.; García-Mera, X.; Fernández, F.; Cordeiro, M.N. Probing the anticancer activity of nucleoside analogues: a QSAR model approach using an internally consistent training set. J. Med. Chem., 2007, 50, 1537-1545.

[12] Kozikowski AP, Roth B, Tropsha A. Why academic drug discovery makes sense. Science, 2006, 313, 1235-1236.

[13] Nwaka, S.; Hudson, A. Innovative lead discovery strategies for tropical diseases. Nat. Rev., 2006, 5, 941-954.

[14] Nwaka S, Ridley RG. Virtual drug discovery and development for neglected diseases through public-private partnerships. Nature Rev. Drug Dis., 2003, 2, 919-928.

[15] Na- Bangchang, K.; Karbwang, J. Current status of malaria chemotherapy and the role of pharmacology in antimalarial drug research and development. Fund. Clin. Pharmacol., 2009, 23, 387-409.

(C) Monzote and Siddiq; Licensee Bentham Open.

This is an open access article licensed under the terms of the Creative Commons Attribution Non-Commercial License (http: //creativecommons.org/licenses/by$\mathrm{nc} / 3.0 /$ ) which permits unrestricted, non-commercial use, distribution and reproduction in any medium, provided the work is properly cited. 